ROCZNIKI HUMANISTYCZNE

Tom LXIX, zeszyt $6-2021$

DOI: https://doi.org/10.18290/rh21696-9

ŁUKASZ TRZECIAK

\title{
WSPÓŁCZESNE POLSKIE NAZWISKA PATRONIMICZNE (Z SUFIKSAMI -ICZ, -OWICZ/-EWICZ) POCHODZENIA ORMIAŃSKIEGO
}

Ormianie przybyli na ziemie polskie ${ }^{1} \mathrm{w}$ XIV wieku. Językiem średniowiecznych osadników był kipczacki (należący do rodziny tureckiej), przejęty przez Ormian krymskich i nadwołżańskich „od Kipczaków (inaczej Połowców, Kumanów) [...]. Istnieje też hipoteza [...], że polscy Ormianie mówili po kipczacku, bo byli w rzeczywistości Kipczakami, schrystianizowanymi przez Kościół ormiański. Język ten nazywany był potocznie tatarskim (tatarcza)" (Stopka i Zięba 181).

Mową późniejszych kolonistów był dialekt „języka ormiańskiego (tzw. aszcharabaru, zwanego «mową pospolitą»). Trudno więc im było porozumieć się z wcześniej osiadłymi tu pobratymcami. Językiem pomocniczym stawał się wówczas polski” (Stopka i Zięba 182). Zdaniem Pisowicza wychodzący z użycia w wieku XVI język kipczacki ustępował miejsca nie tylko językowi polskiemu, ale i ukraińskiemu (zob. NOrm - „Nazwy osobowe Ormian. Próba objaśnienia” - 33). Wymarły ostatecznie w wieku XVII język zapisywany był przez Ormian za pomocą alfabetu ormiańskiego.

W XVIII wieku na Kresach Południowo-Wschodnich pojawiła się kolejna ormiańska fala migracyjna, przybysze z terenów mołdawskich posługiwali się „dialektem należącym do grupy zachodnioormiańskiej i najbliżej spokrewnionym z językiem Ormian rumuńskich” (NOrm 33).

Dr ŁUKASZ TRZECIAK - adiunkt w Katedrze Filologii Polskiej Instytutu Filologii Akademii Pomorskiej w Słupsku; adres do korespondencji: ul. Krzysztofa Arciszewskiego 22 A, 76-200 Słupsk; e-mail: lukasz.trzeciak@apsl.edu.pl. ORCID: https://orcid.org/0000-0003-1999-5004.

${ }^{1} \mathrm{O}$ polskich Ormianach zob. Barącz, Rys dziejów ormiańskich i Żywoty sławnych Ormian w Polsce; Zakrzewska-Dubasowa; Stopka; Machul-Telus; Wasyl. 
Szczególne znaczenie dla Ormian mają więzy pokrewieństwa. Tradycyjna wspólnota rodowa azg składała się z kilku (zazwyczaj sześciu - siedmiu) pokoleń (linie proste i boczne pokrewieństwa), które łączyło pochodzenie od wspólnego przodka. Jedność wspólnoty rodowej wyrażała się m.in. w autoidentyfikacji za pomocą nazwy własnej, wywodzącej się od określenia przodka - założyciela rodu. Nazwa rodowa mogła pochodzić od imienia przodka lub nazwy zawodu założyciela rodu (jeśli zajęcie przodka było kontynuowane przez potomków) albo od nazwy miejsca pochodzenia; do podstaw onimicznych dodawano sufiksy wskazujące na relację przynależności. Obok nazwy rodowej używano również przydomków. Pochodzące od nazwy rodu współcześnie rozumiane nazwisko (orm. azganun 'nazwa rodu'; azg 'ród' + anun - 'nazwa, imię') utrwala się na ziemiach ormiańskich w XIX wieku (zob. Vardanân i in. 307-308). Avetisyan podkreśla, że do ormiańskich sufiksów nazwiskotwórczych należą: -yan, -yanc', -unc '-onc \%-enc \%-anc', -uni, -akan (HAB - Hayoc'azganunneri bararan - V).

„Pierwsze pokolenia Ormian polskich obok imienia używały form odimiennych, pochodzących od imienia ojcowskiego (patronimików). W języku kipczackim tworzono je przez dodanie do imienia ojcowskiego końcówki -oglu, -ohlu (tzn. syn)" (Stopka i Zięba 180); rzadziej używane były formy grabarowe (staroormiańskie) z przyrostkami typu -yanc", -unc\%-onc\%-enc\%-anc", wyparte $\mathrm{w}$ następnych wiekach przez formant -yan. Otoczenie słowiańskie (polskie i ruskie - ukraińskie) wpływało na stopniową slawizację ormiańskich antroponimów - kipczackie leksemy czy ormiańskie sufiksy patronimiczne zastępowano słowiańskimi sufiksami patronimicznymi -icz, -owicz/-ewicz:

\begin{abstract}
Początkowo formy kipczacka i słowiańska wystepowały przemiennie w zależności od kontekstu sytuacyjnego. W dwujęzycznym dokumencie [...] [z] 1617 roku kupcy ormiańscy w wersji polskiej podpisali się: «der Łukaszowic, Iwaszkowicz, Diradurowic, Piotrowic», natomiast w wersji kipczackiej: «der Lukasz oglu, Iwaszko oglu, Diradur oglu, Petre oglu». Z biegiem czasu Ormianie polscy przyjmowali już wyłącznie przydatniejsze w użyciu wśród miejscowej ludności formy słowiańskie. W ten sposób syn Minasa stał się Minasowiczem lub Minasiewiczem, syn Serebka Serebkowiczem, syn Torosa - Torosowiczem lub Torosiewiczem, syn Axenta Axentowiczem (Stopka i Zięba 180-181).
\end{abstract}

Odziedziczony z prasłowiańszczyzny przyrostek *-itjb polszczyzna przekształciła $\mathrm{w}$ sufiks -ic, zaś pod wpływem wschodniosłowiańskim w -icz; równolegle, zgodnie z prawem rozwoju analogicznego, rozpowszechniały się formanty złożone z -ow-: -owic > -owicz ${ }^{2}$. Rymut zauważa, iż:

\footnotetext{
${ }^{2} \mathrm{O}$ ewolucji formalnej i semantycznej przyrostka zob. Magda-Czekaj (79-85).
} 
Oboczność -icz||-owicz została wytworzona już w epoce prasłowiańskiej. Forma -ic występowała głównie w wyrazach zakończonych w mianowniku liczby pojedynczej na samogłoskę $-a$, natomiast -owic na spółgłoskę. Ta repartycja została $\mathrm{z}$ biegiem wieków zachwiana. W historii przyrostka -owic(z) nastąpiła też zmiana w samogłosce początkowej. Na obszarze Wielkopolski, Mazowsza oraz Pomorza po spółgłoskach miękkich, a także po $c, c z, d z, s z, \dot{z}$, które niegdyś były miękkie, -o- przeszło w -e-, stąd formy typu Wojewic, Jaszewic. [...]. Druga zmiana dotyczy też samogłoski $o$. Mianowicie po spółgłoskach tylnojęzykowych $k, g$, ch następuje przejście w $e$. Zmiana ta dokonała się w tym wypadku pod wpływem białoruskim i zaszła stosunkowo późno. Pierwsze zapisy typu Jankiewicz pochodzą z końca XV w. z [K]resów [P]ółnocno-[W]schodnich. Zmiana ta nie została przeprowadzona do końca i dziś mamy Jankiewicz obok Jankowicz, Markiewicz obok Markowicz, Eustachiewicz i Estachowicz, Langiewicz i Langowicz. Pod wpływem form typu Jankiewicz, Langiewicz pojawiły się też Drozdewicz, Kiełbasiewicz, Kaczmarewicz, Górewicz. Do końca średniowiecza formy na -ic, -owic określały pochodzenie od ojca, były patronimikami [...]. Po wieku XV maleje żywotność odojcowskich form na -ic, -owic. Na ich miejsce wchodzą formacje zdrobniałe na -ik, -ek, -czak (R - Nazwiska Polaków. Stownik historyczno-etymologiczny, 1: XLVIII-XLIX).

Kresowe początki formantu -icz, -owicz/-ewicz tłumaczą popularność tego typu patronimików wśród spolszczonych potomków Ormian na terenach wschodniej I Rzeczypospolitej. Zdaniem Wolnicz-Pawłowskiej i Szulowskiej ten typ nazwisk „na Kresach związany jest z warstwą szlachecką znacznie silniej, niż w Polsce. Jako model nazwiska prestiżowego, stosowanego przez ówczesną elitę, oddziaływał na formowanie się nazwisk innych warstw, przede wszystkim mieszczaństwa w większych ośrodkach miejskich" (183). Jak podkreślają Stopka i Zięba, od XVII wieku ormiańsko-polskie „patronimika traciły charakter indywidualny i stawały się nazwiskami dziedzicznymi (rodowymi)" (181).

Ormianie zaznaczyli swoją obecność w okresie kształtowania się polskiego nazwiska (zob. Kaleta, Ewolucja nazwisk stowiańskich. Studium teoretyczno-porównawcze 16-19); należy zaznaczyć, iż - zdaniem Rymuta - długotrwały proces przekształcania się systemu jednonazwowego (jednoimiennego) $\mathrm{w}$ dwunazwowy (dwuimienny) rozpoczął się na ziemiach polskich „dopiero około połowy XIII w., a w pełni upowszechnił się pod koniec XVIII w.” („Nazwiska” 149).

Antroponimy staropolskich Ormian znajdziemy w SSNO (Stownik staropolskich nazw osobowych), a ich objaśnienie w NOrm.

Ormiańskie nazwy osobowe doby średniopolskiej notowane są w AntrP (Antroponimia Polski od XVI do końca XVIII wieku); zdecydowana większość antroponimów pochodzi z pracy Buczyńskiego („Patronimika ormiańskie w XVII-wiecznym Zamościu"), bazującego na ustaleniach Hanusza (HOrm - „O nazwiskach Ormian polskich”) i wynikach własnych dociekań. 
Nowopolskie nazwiska ormiańskie były przedmiotem opracowań Hanusza (HOrm i „Einige slavische Namen armenischer und türkischer Herkunft”); materiał badawczy pochodził z ekscerpcji tekstów publikacji Barącza (Rys dziejów ormiańskich i Żywoty stawnych Ormian w Polsce) oraz badań terenowych przeprowadzonych w Kutach nad Czeremoszem. Jak zaznaczał Hanusz, „Zbiór ten da się jeszcze znacznie uzupełnić nazwiskami dawniejszymi ze starych aktów i dzisiejszymi ze spisów urzędowych naszych parafij ormiańskich. Szanowni koledzy mogliby go też nieco uzupełnić ze swych katalogów szkolnych, za co im podpisany byłby nader wdzięczny" (HOrm 565). Przedwcześnie zmarły językoznawca (w 1887, zatem rok po wydaniu powyższych artykułów) nie zdążył zrealizować swych badawczych zamierzeń.

Obecność nazw pochodzenia ormiańskiego w polskiej antroponimii ${ }^{3}$ odnotowali m.in. Bystroń (259-261), Słuszkiewicz („Orm. Minasowicz || Minasiewicz itp.") i Rymut (R1: LXXV).

Potrzeba uzupełnienia zbioru nowopolskich antroponimów pochodzenia ormiańskiego (na co już Hanusz zwracał uwagę) stała się impulsem do powstania niniejszej pracy. Po drugie, analiza językowa nazw osobowych o genezie ormiańskiej powinna uwzględniać ustalenia współczesnej ormiańskiej antroponomastyki. Opracowanie współcześnie używanych nazwisk polskich Ormian należy łączyć z analizą historycznojęzykową onimów. Czwarty powód wynika $\mathrm{z}$ tego, że opracowania antroponimów mających ormiańską genezę nie są wolne od braków (np. HOrm notuje nazwisko Piramowicz, ale nie podaje żadnych objaśnień etymologiczno-motywacyjnych) i omyłek (np. Buczyński umieszcza antroponim Minasowic(z) w grupie patronimików opartych na leksemach tureckich i arabskich). Po piąte, ujednolicenia wymaga sposób konwersji pisma ormiańskiego ( $\mathrm{w}$ niniejszej pracy stosuję międzynarodową transliterację naukową).

Ormiańskie antroponimy potraktowałem jako bazę leksykalną współczesnych polskich nazwisk, których zasób i formy znaleźć można w SNW (Słownik nazwisk współcześnie w Polsce używanych). Do leksemów ormiańskich zaliczam również zarmenizowane antroponimy genetycznie obce. W opracowaniu ujmuję wyłącznie nazwiska derywowane za pomocą sufiksów

\footnotetext{
${ }^{3}$ Aspekt językowej asymilacji antroponimii ormiańskiej znajduje jeszcze pełniejszy wyraz we wtopieniu się Ormian w polską kulturę narodową; spośród licznych przykładów przywołam jedynie kilka (zawężając wybór wyłącznie do analizowanych w niniejszym opracowaniu antroponimów): Kajetan Abgarowicz, pseud. Abgar Sołtan (1856-1909), powieściopisarz, nowelista; Teodor Axentowicz (1859-1938), malarz; Józef Epifani Minasowicz (1718-1796), edytor, tłumacz, poeta; Grzegorz Piramowicz (1735-1801), pedagog, działacz oświatowy, pisarz, jezuita.
} 
patronimicznych -icz, -owicz/-ewicz. Przedmiotem odrębnego opracowania będą nazwiska utworzone za pomocą pozostałych formantów (np. -ek - Torosek $<$ orm. im. T'oros; $-k o-$ Bołoszko $<$ orm. im. Połos z fon. zachorm.; -ów - Awaków < orm. im. Avag z fon. zachorm.; -(ow)ski - Piramowski< orm. n. os. $P$ 'iran lub P'irum) oraz niederywowane (np. Bołosz, Bołoz < orm. im. Połos z fon. zachorm.; Minas, Minasz < orm. im. Minas; Toros < orm. im. T'oros).

Nazwiska umieszczam w słowniku, którego artykuły hasłowe zostały ułożone w porządku alfabetycznym i składają się z następujących części: wyrazu hasłowego - hasłem jest wyróżnione wytłuszczeniem nazwisko podane w mianowniku liczby pojedynczej (ewentualne warianty podaję po przecinku), po nim - w nawiasie - zamieszczam analizę historycznojęzykową antroponimów, wskazując, czy były one notowane w źródłach historycznych (SSNO, AntrP - podaję tom, w którym notowana jest dana nazwa własna i datę notowania lub zaznaczam brak poświadczenia - oraz HOrm), zaś po poświadczeniu nazwiska we współczesnym źródle - SNW - podaję liczbę jego nosicieli ${ }^{4}$ oraz rozmieszczenie geograficzne; podając objaśnienia etymologiczno-motywacyjne, stosuję zapis z dwukropkiem (z pojęciem motywacji wiąże się analiza onimu, zaś z etymologią - analiza apelatywu; połączenie obu narzędzi umożliwia analizę nazwy własnej uzupełnioną o objaśnienia etymologiczne), przywołuję również ormiański antroponim (za HAB); ponadto, jeśli w SEMot (Słownik etymologiczno-motywacyjny staropolskich nazw osobowych) lub $\mathrm{R}$ przedstawione są inne objaśnienia etymologiczno-motywacyjne, przywołuję je - po średniku - wskazując źródło (SEMot: NCh - Nazwy osobowe pochodzenia chrześcijańskiego, NOrm; R); artykuł hasłowy kończę kropką.

Abgarowicz (SSNO: brak; AntrP I: XVIII; HOrm; SNW I: 29 - Wa:21, Gd:2, Wb:6) : n. os. Abgar + suf. -owicz< orm. (z asyr.) im. Abgar, por. orm. n. os. Abgaryan (HAB).

Agopsowicz (SSNO: brak; AntrP I: XVIII; HOrm; SNW I: 67 - Wa:1, BB:8, Gd:2, Go:5, Ka:3, Kr:8, Ks:4, Łd:3, NS:1, Ol:1, Op:4, Rz:3, Sz:6, Wr:13, ZG:5), Hasso-Agopsowicz (SSNO, AntrP, HOrm: brak; SNW IV: 10 Ol:5, Wb:5) : n. os. Agop(o)s + suf. -owicz < orm. im. Hakob(os) z fon. zachorm. < hebr. Jaaqob (יעְעבב) 'Jakub', por. orm. n. os. Hakobyan (HAB).

Aksentowicz (SSNO: brak; AntrP I: 1624-1700 - Aksantowicz; HOrm; SNW I: 25 - Go:10, K1:4, Op:2, St:4, ZG:5), Axentowicz (SSNO, AntrP: brak; HOrm: brak; SNW I: 12 - Wa:7, Ka:3, Kr:1, Łd:1), Oksentowicz (SSNO,

\footnotetext{
${ }^{4}$ Rymut zaznacza, iż „,w banku danych PESEL występują nazwiska z określeniem częstotliwości 0 . Do tej grupy zaliczono osoby, o których w banku nie ma bliższych informacji (np. brak miejsca zamieszkania). Należą tu także osoby, które w 1990 r. już nie żyły” SNW (1: VIII-IX).
} 
AntrP, HOrm: brak; SNW VII: 64 - Wa:2, Bs:36, By:6, Gd:9, Lu:7, Sd:3, Za:1), Oksientowicz (SSNO, AntrP, HOrm: brak; SNW VII: 12 - Wa:1, Bs:8, Sk:3), Oksiętowicz (SSNO, AntrP, HOrm: brak; SNW VII: 3 - Wa:1, Bs:2) : n. os. Aksent(y)/Oks(i)ent(y) + suf. -owicz < orm. (z gr.-łac.) im. Ôk'sentios 'Auksencjusz/Auksenty', por. orm. n. os. Ôk'sentyan (HAB); < wsł. im. Avksentij/ Oksenty (R).

Aramowicz (SSNO: brak; AntrP I: 1627; HOrm: brak; SNW I: 167 - Wa:2, Bs:24, By:1, Ci:4, Cz:7, Gd:10, Go:4, Ka:10, Lg:2, Lu:4, Łd:5, Ol:45, Op:2, Os:5, Pl:7, Pt:2, Sr:3, Sz:18, To:5, Wb:1, Wr:6) : im. Aram + suf. -owicz< orm. im. Aram, por. orm. n. os. Aramyan (HAB); < bibl. im. Aram (אָָר), (m.in. Aram, syn Sema, eponim Aramejczyków), por. hebr. ap. ’ărām 'wysoki, podwyższony; wysokość, wzniesienie' (NCh).

Arewicz (SSNO: brak, AntrP I: 1624-1700 - Ariewowicz; HOrm: brak; SNW I: 0) : n. os. Arew + suf. -icz< orm. im. Arew, por. orm. ap. arew 'słońce', orm. n. os. Arewyan (HAB).

Awakowicz (SSNO: brak; AntrP I: 1624-1700; HOrm; SNW I: 31 - BB:2, Gd:4, Ka:15, Kr:1, Tb:3, Wr:3, ZG:3), Owakowicz (SSNO, AntrP, HOrm: brak; SNW VII: 0) : n. os. Awak/Owak + suf. -owicz < orm. im. Avag z fon. zachorm., por. orm. ap. avag 'starszy; główny', orm. n. os. Avagyan (HAB); < łac. avia 'babka' (R).

Axentowicz Zob. Aksentowicz.

Bochosiewicz Zob. Bohosiewicz.

Bohasiewicz Zob. Bohosiewicz.

Bohosiewicz (SSNO, AntrP: brak; HOrm; SNW I: 73 - BB:1, Ka:31, Kr:29, Lg:1, Sz:6, Wb:2, Wr:3), Bochosiewicz (SSNO, AntrP, HOrm: brak; SNW I: 1 - Kr:1), Bohasiewicz (SSNO, AntrP, HOrm: brak; SNW I: 2 - Wr:2), Bohoszewicz (SSNO, AntrP, HOrm: brak; SNW I: 0) : n. os. Bo(c)hos $(z) /$ Bohas + suf. -ewicz < orm. im. Połos z fon. zachorm. < łac. im. Paulus 'Pawel', por. orm. n. os. Połosyan (HAB); < im. zł. typu Boguchwat, Bogusław z ukr. lub czes. $-h-\mathrm{w}$ miejsce $-g$ - $(\mathrm{R})$.

Bohoszewicz Zob. Bohosiewicz.

Charutonowicz (SSNO: brak; AntrP I: 1558 - Charytonowicz; HOrm: brak; SNW II: 0) : n. os. Charuton + suf. -owicz < orm. im. Harut'yun, por. orm. ap. harut'yun 'zmartwychwstanie', orm. n. os. Harut'yunyan (HAB); może < im. Charyton (R).

Dadurewicz (SSNO, AntrP, HOrm: brak; SNW II: 1 - Su:1) : n. os. Dadur + suf. -ewicz < orm. n. os. Dadur < im. Astvacadur, por. orm. n. os. Daduryan 
(HAB); < ap. dada 'dziadek; babka (w języku dziecinnym)' lub od gw. dadać 'paplać, gaworzyć' (R).

Danabidowicz Zob. Donabidowicz.

Donabidowicz (SSNO, AntrP: brak; HOrm - Donabiedowicz; SNW II: 53 - Ka:6, Ki:17, Kr:4, Lu:5, Po:1, Wr:8, ZG:12), Danabidowicz (SSNO, AntrP, HOrm: brak; SNW II: 0) : n. os. Donabi(e)d/Danabi(e)d + suf. -owicz < orm. n. os. Tonapet z fon. zachorm., por. orm. ap. ton 'święto', pet 'przywódca, zwierzchnik, przełożony', orm. n. os. Tonapetyan (HAB); < podst. dan-, por. ap. dany, dań, im. Daniel, Bogdan (R).

Dongiewicz Zob. Donigiewicz.

Doniegiewicz Zob. Donigiewicz.

Donigiewicz (SSNO, AntrP: brak; HOrm; SNW II: 109 - Wa:20, BB:3, Go:24, Ka:13, Ko:14, Kr:3, Łd:1, NS:2, Op:3, Pt:4, Wb:4, Wr:17, ZG:1), Dongiewicz (SSNO, AntrP, HOrm: brak; SNW II: 0), Doniegiewicz (SSNO, AntrP, HOrm: brak; SNW II: 0), Tonikiewicz (SSNO, AntrP, HOrm: brak; SNW IX: 1 - Kr:1) : n. os. Don $(i)(e) g /$ Tonik + suf. -ewicz< orm. n. os. Tonik (z fon. zachorm.) < orm. ap. ton 'święto' lub orm. n. os. z Ton-, np. Ton, Tonakan, Tonapet, Tonavag, por. orm. n. os. Tonikyan (HAB); może $<$ ap. dęga 'pręga, szrama; tęcza' lub ap. dąg 'siła, zdrowie' albo < podst. ton-, por. ap. toń 'głębia', 'krytyczna sytuacja; przerębla', tonąc 'pogrążać się', ton 'dźwięk; zabarwienie czegoś', im. Antoni (R).

Hasso-Agopsowicz Zob. Agopsowicz.

Kierkorowicz Zob. Kirkorowicz.

Kirkorowicz (SSNO: brak; AntrP II: 1629; HOrm; SNW IV: 3 - Gd:1, Ka:1, Op:1), Kierkorowicz (SSNO, AntrP, HOrm: brak; SNW IV: 1 - Kr:1) : n. os. Ki(e)rkor + suf. -owicz < orm. (z gr.) im. Grigor 'Grzegorz' z fon. zachorm., por. orm. n. os. Grigoryan (HAB).

Manugiewicz (SSNO: brak; AntrP II 1779/1780; HOrm; SNW VI: 85 Wa:15, JG:9, Ka:1, Ki:2, Kr:4, Łd:7, NS:1, Op:1, Po:4, Sł:3, Sz:3, Wb:12, Wr:14, ZG:9), Manukiewicz (SSNO, AntrP, HOrm: brak; SNW VI: 0) : n. os. Manug/Manuk + suf. -ewicz < orm. im. Manuk (z fon. zachorm.), por. orm. ap. manuk 'chłopiec; dziecko', orm. n. os. Manukyan (HAB); < podst. Man-, por. im. zł. typu Manomir, im. na Ma-, typu Maria, Emanuel, wsł. Maniło, niem. n. os. z członem man-, typu Herman, niem. n. os. od Mann 'człowiek, mężczyzna' (R).

Manukiewicz Zob. Manugiewicz.

Minasiewicz (SSNO: brak; AntrP III: 1754; HOrm; SNW VI: $100-$ Wa:22, Ci:4, Gd:12, JG:1, Ka:6, Ko:4, Ło:1, Os:46, Po:1, Sd:2, Sz:1), 
Minasowicz (SSNO: brak; AntrP III: 1659/1660; HOrm; SNW VI: 12 Wa:5, Kr:5, Ls:2), Minaszewicz (SSNO: brak; AntrP III: 1700/1701; HOrm: brak; SNW VI: 2 - Wa:2), Miniasiewicz (SSNO, AntrP, HOrm: brak; SNW VI: 1 - Wa:1) : n. os. Min(i)as(z) + suf. -ewicz/-owicz < orm. (z egip. lub gr.) im. Minas, por. orm. n. os. Minasyan (HAB, NOrm); < podst. min-, por. ap. mina, minać, im. zł. Minigniew (R).

Minasowicz Zob. Minasiewicz.

Minaszewicz Zob. Minasiewicz.

Miniasiewicz Zob. Minasiewicz.

Norsesowicz (SSNO, AntrP: brak; HOrm; SNW VI: 26 - Wa:3, Go:13, JG:2, Lg:3, Wr:5) : n. os. Norses + suf. -owicz< orm. (z pahl.) im. Nerses, por. orm. n. os. Nersesyan (HAB).

Ochanowicz Zob. Ohanowicz.

Odrowąż-Piramowicz Zob. Piramowicz.

Ohanowicz (SSNO, AntrP: brak; HOrm; SNW VII: 15 - Wa:2, BB:1, JG:1, Ka:1, Ko:2, Łd:1, Op:1, Wr:6), Ochanowicz (SSNO: brak; AntrP III: 1793; HOrm: brak; SNW VII: 0) : n. os. $O(c)$ han + suf. -owicz < orm. n. os.

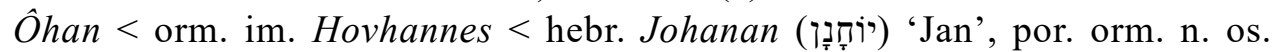
Ôhanyan, Oxanyan (HAB); < ap. oganiać się 'opędzać się' (R).

Oksentowicz Zob. Aksentowicz.

Oksientowicz Zob. Aksentowicz.

Oksiętowicz Zob. Aksentowicz.

Owakowicz Zob. Awakowicz.

Piramowicz (SSNO: brak; AntrP III: 1675; HOrm; SNW VII: 6 - Ka:6), Odrowąż-Piramowicz (SSNO, AntrP, HOrm: brak; SNW VII: 23 - By:1, Sł:13, Sz:5, Wł:4), Piramowicz-Odrowąż (SSNO, AntrP, HOrm: brak; SNW VII: 7 - Sł:7), Pirianowicz (SSNO, AntrP, HOrm: brak; SNW VII: 14 - Wa:7, Ka:2, Ol:4, Su:1), Pirijanowicz (SSNO, AntrP, HOrm: brak; SNW VII: 2 Ka:2), Pirjanowicz (SSNO, AntrP, HOrm: brak; SNW VII: 16 - JG:7, Su:5, Wb:4), Pirmowicz (SSNO, AntrP, HOrm: brak; SNW VII: 1 - Go:1) : n. os. Piram/Pir(i)(j)an + suf. -owicz < orm. (z pers.) n. os. P'iran lub orm. (z pers.tur.) n. os. $P$ 'irum, por. orm. n. os. $P$ 'iranyan, $P$ 'irumyan (HAB).

Piramowicz-Odrowąż Zob. Piramowicz.

Pirianowicz Zob. Piramowicz.

Pirijanowicz Zob. Piramowicz.

Pirjanowicz Zob. Piramowicz.

Pirmowicz Zob. Piramowicz.

Tonikiewicz Zob. Donigiewicz. 
Torosiewicz (SSNO: brak; AntrP V: 1782, 1591 - Torosowicz; HOrm; SNW IX: 15 - Wa:6, Gd:2, Ka:2, Wb:1, Wr:4) : n. os. Toros + suf. -ewicz < orm. im. T'oros < orm. (z gr.) im. T'eodoros 'Teodor', por. orm. n. os. T'orosyan (HAB); $<$ ap. tor 'droga, trasa', torować 'przecierać szlak', niem. n. os. Tor (R).

Wachanowicz (SSNO, AntrP, HOrm: brak; SNW X: 0) : n. os. Wa(c)han + suf. -owicz < orm. (z pahl.) im. Vahan, por. orm. n. os. Vahanyan (HAB); < im. na Wa-, typu Wacław, Wawrzyniec (R).

Wartanowicz (SSNO: brak; AntrP VI: 1662; HOrm; SNW X: 13 - Wa:4, Op:1, Wr:8), Wartonowicz (SSNO, AntrP, HOrm: brak; SNW X: 0) : n. os. Wartan/Warton + suf. -owicz < orm. im. Vardan z fon. zachorm., por. orm. n. os. Vardanyan (HAB); < podst. wart-, por. ap. wart(y), wartki 'szybko płynący', warta 'straż', n. m. Warta (R).

Warteresiewicz (SSNO: brak; AntrP VI: 1635 - Wartarasiewicz; HOrm; SNW X: 6 - Wa:4, Ka:1, Op:1) : n. os. Warteres + suf. -ewicz< orm. im. Varderes z fon. zachorm., por. ap. varderes 'różanolicy', vard 'róża' + eres 'twarz; policzek', orm. n. os. Varderesyan (HAB).

Wartonowicz Zob. Wartanowicz.

Wartykiewicz (SSNO, AntrP: brak; HOrm - Wartykowicz; SNW X: 0) : n. os. Wartyk + suf. -ewicz < orm. n. os. Vardik z fon. zachorm. $<$ orm. im. Vardan lub ap. vard 'róża', por. orm. n. os. Vardikyan (HAB); < podst. wart-, por. wart(y), wartki 'szybko płynący', warta 'straż', n. m. Warta (R).

Zadurowicz (SSNO, AntrP: brak; HOrm; SNW X: 31 - Wa:5, Cz:4, Gd:2, Go:1, Ka:1, Kr:1, Lg:1, Łd:1, Op:12, Wr:3), Żadurowicz (SSNO, AntrP, HOrm: brak; SNW X: 1 - Op:1) : n. os. Zadur/Żadur + suf. -owicz < orm. n. os. Zadur/Catur < im. Astvacadur, por. orm. n. os. Zaduryan, Caturyan (HAB); < ap. zadurzyć/zadurzeć 'ogłuszyć; upoić, zawrócić głowę' lub za+stp. dura 'dziura' (R).

Zadygowicz (SSNO, AntrP: brak; HOrm - Zadygiewicz; SNW X: 40 Bs:28, Wr:12), Zadykiewicz (SSNO, AntrP, HOrm: brak; SNW X: 2 - Wa:2), Zadykowicz (SSNO, AntrP, HOrm: brak; SNW X: 530 - Wa:21, Bs:420, BB:4, Cz:2, Gd:3, JG:3, Ka:1, Ło:7, Łd:2, Ol:9, Op:2, Os:4, Su:4, Sz:8, To:7, Wb:12, Wr:5, ZG:16) : n. os. Zadyg/Zadyk + suf. -owicz/-ewicz< orm. im. Zatik z fon. zachorm., por. orm. heortonim Zatik 'Wielkanoc', orm. n. os. Zatikyan (HAB).

Zadykiewicz Zob. Zadygowicz.

Zadykowicz Zob. Zadygowicz.

Zarugiewicz (SSNO, AntrP, HOrm: brak; SNW X: 1 - Bs:1), Zarukiewicz (SSNO, AntrP, HOrm: brak; SNW X: 9 - Wa:4, BP:2, Kr:2, Wł:1), Zerygiewicz (SSNO, AntrP: brak; HOrm; SNW X: 4 - Ko:3, Kr:1), Żerygiewicz (SSNO, 
AntrP, HOrm: brak; SNW X: 0) : n. os. Zaruk/Zarug/Zeryg/Żeryg + suf. -ewicz $<$ orm. n. os. Zaruk lub Zeruk (z fon. zachorm.) < orm. n. os. Caruk albo Caruk bądź Ceruk czy orm. (z pers.) im. Zaruhi, por. orm. ap. car 'drzewo', ceruk/ cerik 'staruszek, starzec', orm. n. os. Zarukyan, Zerukyan, Carukyan, Carukyan, Cerukyan (HAB); może < ap. zaręka 'poręka, gwarancja' (R).

Zarukiewicz Zob. Zarugiewicz.

Zerygiewicz Zob. Zarugiewicz.

Żadurowicz Zob. Zadurowicz.

Żerygiewicz Zob. Zarugiewicz.

Uwzględnienie notowania w źródłach historycznych (SSNO, AntrP) oraz współczesnych (SNW) pozwala określić chronologię pojawiania się nazw osobowych będących przedmiotem niniejszego opracowania: począwszy od doby średniopolskiej (brak w materiale staropolskim), przy pewnej grupie nazwisk bez określonej chronologii.

Wśród polskich nazwisk patronimicznych (z sufiksami -icz, -owicz/-ewicz) pochodzenia ormiańskiego przeważają antroponimy o niewielkiej liczbie nosicieli. W rozmieszczeniu geograficznym nazwisk wskazać można dominantę na ziemiach zachodnich i północnych współczesnej Polski (miejsca powojennej migracji kresowej ludności przedwojennej II Rzeczypospolitej, w tym także Ormian) oraz stolicy. Uwzględnienie nazwisk utworzonych za pomocą pozostałych formantów oraz niederywowanych (co będzie przedmiotem odrębnego opracowania) umożliwi pełniejszą analizę stratygrafii antroponimii polskich Ormian.

W opracowaniu zawarto 57 antroponimów (ujętych w 25 hasłach słownikowych), które zawdzięczają pochodzenie (lub też mogą zawdzięczać) leksemom ormiańskim.

W analizowanym materiale największą grupę stanowią nazwiska derywowane za pomocą sufiksu -owicz (34 nazwiska, ok. 59,65\% ogółu): Abgarowicz, Agopsowicz/Hasso-Agopsowicz, Aksentowicz, Aramowicz, Awakowicz, Axentowicz, Charutonowicz, Danabidowicz, Donabidowicz, Kierkorowicz, Kirkorowicz, Minasowicz, Norsesowicz, Ochanowicz, Ohanowicz, Oksentowicz, Oksientowicz, Oksiętowicz, Owakowicz, Piramowicz/Odrowąż-Piramowicz/ Piramowicz-Odrowąż, Pirianowicz, Pirijanowicz, Pirjanowicz, Pirmowicz, Wachanowicz, Wartanowicz, Wartonowicz, Zadurowicz, Zadygowicz, Zadykowicz, Żadurowicz.

Formant -ewicz utworzył 22 nazwiska (38,6\% ogółu): Bochosiewicz, Bohasiewicz, Bohosiewicz, Bohoszewicz, Dadurewicz, Dongiewicz, Doniegiewicz, Donigiewicz, Manugiewicz, Manukiewicz, Minasiewicz, Minaszewicz, Minia- 
siewicz, Tonikiewicz, Torosiewicz, Warteresiewicz, Wartykiewicz, Zadykiewicz, Zarugiewicz, Zarukiewicz, Zerygiewicz, Żerygiewicz.

Za pomocą najmniej produktywnego przyrostka -icz utworzono 1 nazwisko $(1,75 \%$ ogółu): Arewicz.

Tematy słowotwórcze derywatów na -owicz zakończone są na spółgłoski: $d$ - Danabid-owicz, Donabid-owicz; $g$ - Zadyg-owicz; $k$ - Awak-owicz, Owak-owicz, Zadyk-owicz; m-Aram-owicz, Piram-owicz, Pirm-owicz; $n$ Charuton-owicz, Ochan-owicz, Ohan-owicz, Pirian-owicz, Pirijan-owicz, Pirjan-owicz, Wachan-owicz, Wartan-owicz, Warton-owicz; $r$-Abgar-owicz, Kierkor-owicz, Kirkor-owicz, Zadur-owicz, Żadur-owicz; s-Agops-owicz, Minas-owicz, Norses-owicz; $t$ - Aksent-owicz, Axent-owicz, Oksent-owicz, Oksient-owicz, Oksięt-owicz.

W wygłosie tematów słowotwórczych derywatów na -ewicz występują spółgłoski: g' - Dongi-ewicz, Doniegi-ewicz, Donigi-ewicz, Manugi-ewicz, Zarugi-ewicz, Zerygi-ewicz, Żerygi-ewicz; $k^{\prime}-$ Manuki-ewicz, Toniki-ewicz, Wartyki-ewicz, Zadyki-ewicz, Zaruki-ewicz; r - Dadur-ewicz; $\check{s}-$ Bohoszewicz, Minasz-ewicz; 'ś-Bochosi-ewicz, Bohasi-ewicz, Bohosi-ewicz, Minasi-ewicz, Miniasi-ewicz, Torosi-ewicz, Warteresi-ewicz.

Oboczność -owic(z)/-ewic(z) obserwujemy zatem w następujących przypadkach: $g$ : $g^{\prime}$, np. Zadyg-owicz, Donigi-ewicz; $k: k^{\prime}$, np. Zadyk-owiczl Zadyki-ewicz; r, np. Zadur-owicz, Dadur-ewicz; s : ̌s : ś, np. Minas-owiczl Minasz-ewicz/Minasi-ewicz.

Antroponimy będące przedmiotem niniejszego opracowania są egzemplifikacyjnym potwierdzeniem opinii Kalety, podkreślającej, że nazwy własne są bogactwem narodu, gdyż mogą kryć w sobie wiedzę m.in. o „historii politycznej i społecznej, o historii kultury i religii, [...], o związkach z innymi krajami, [...]. Są też świadectwem przynależności etnicznej człowieka i ziemi do narodu, wyznacznikiem narodowości” („Teoria nazw własnych” 15).

Bazę leksykalną analizowanych antroponimów stanowią leksemy genetycznie ormiańskie (Aramowicz < Aram; Arewicz < Arew; Awakowicz/Owakowicz $<$ Avag; Charutonowicz < Harut'yun; Dadurewicz < Dadur; Donabidowiczl Danabidowicz < Tonapet; Donigiewicz/Dongiewicz/Doniegiewicz/Tonikiewicz $<$ Tonik; Manugiewicz/Manukiewicz < Manuk; Wartanowicz/Wartonowicz < Vardan; Warteresiewicz < Varderes; Wartykiewicz $<$ Vardik; Zadurowicz/Żadurowicz $<$ Zadur/Catur; Zadygowicz/Zadykiewicz/Zadykowicz $<$ Zatik; Zarugiewicz/Zarukiewicz/Zerygiewicz/Żerygiewicz $<$ Zaruk/Zeruk $^{5}<$ Caruk/Caruk/ Ceruk) oraz zarmenizowane leksemy pochodzenia asyryjskiego (Abgarowicz

\footnotetext{
${ }^{5}$ Por. zarmenizowany leksem genetycznie perski.
} 
$<$ Abgar), egipskiego (Minasiewicz/Minasowicz/Minaszewicz/ Miniasiewicz $<$ Minas $^{6}$ ), hebrajskiego (Agopsowicz/Hasso-Agopsowicz < Hakob(os); Ohanowicz/Ochanowicz < Ôhan), greckiego (Kirkorowicz/Kierkorowicz < Grigor; Minasiewicz/Minasowicz/Minaszewicz/Miniasiewicz $<$ Minas $^{7}$; Torosiewicz $<$ T'oros), grecko-łacińskiego (Aksentowicz/Axentowicz/ Oksentowicz/Oksientowicz/Oksiętowicz < Ôk'sentios), łacińskiego (Bohosiewicz/ Bochosiewicz/Bohasiewicz/Bohoszewicz $<$ Połos), perskiego ${ }^{8}$ (Norsesowicz < Nerses; Piramowicz/Odrowąż-Piramowicz/Piramowicz-Odrowąż/Pirianowicz/

Pirijanowicz/Pirjanowicz/Pirmowicz $<$ P'iran'; Wachanowicz $<$ Vahan; Zarugiewicz/Zarukiewicz/Zerygiewicz/Żerygiewicz $<$ Zaruk/Zeruk $^{10}<$ Zaruhi) i persko-tureckiego (Piramowicz/Odrowąż-Piramowicz/Piramowicz-Odrowąż/ Pirianowicz/Pirijanowicz/Pirjanowicz/Pirmowicz $<P^{\text {'irum }}{ }^{11}$ ).

Naturalne polszczenie podstaw ormiańskich wynika $\mathrm{z}$ różnic systemowych między językami ormiańskim i polskim; poniżej przedstawiam uwagi o ich fonetyczno-graficznych adaptacjach.

Abgarowicz - pol. Abgar < orm. Abgar; Agopsowicz - orm. Hakob(os) $\mathrm{z}$ fon. zachorm. (Hagopos) $>$ pol. Agops z odrzuceniem przydechowego $h$ - oraz zanikiem -o- w sylabie wygłosowej; Aksentowicz/Axentowicz, Oksentowicz, Oksientowicz/Oksiętowicz - orm. Ôk'sentios > pol. Oksent(y) z zani-

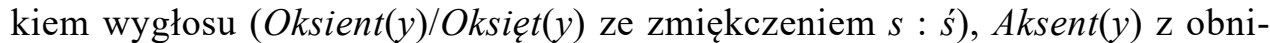
żeniem artykulacji $o$ do $a$ oraz zanikiem wygłosu; Aramowicz - pol. Aram < orm. Aram; Arewicz - pol. Arew < orm. Arew; Awakowicz, Owakowicz orm. Avag z fon. zachorm. (Avak) > pol. Awak, Owak z podwyższeniem artykulacji $a$ do o; Bohosiewicz/Bochosiewicz, Bohasiewicz, Bohoszewicz orm. Potos z fon. zachorm. (Bołoz) $>$ pol. Bo(c)hos, Bohosz z pol. $h$ jako bliskim artykulacyjnie orm. $l$ (w polskiej transkrypcji popularnej fonetycznej - gh) (Bohas z obniżeniem artykulacji $o$ do $a$ ), w temacie alternacja $s: \grave{s}: \check{s}$ (mieszanie spółgłosek szczelinowych); Charutonowicz - orm. Harut'yun $>$ pol. Charuton z obniżeniem artykulacji $u$ do $o$ oraz twardym $t$ jako bliskim artykulacyjnie orm. $t^{\prime} ;$ Dadurewicz - pol. Dadur $<$ orm. Dadur; Donabidowicz, Danabidowicz - orm. Tonapet z fon. zachorm. (Donabed) > pol. Donabid z podwyższeniem artykulacji $e$ do $i$ oraz wynikającą stąd alternacją $b: b^{\prime}$ (Danabid z obniżeniem artykulacji $o$ do $a$ ); Donigiewicz,

\footnotetext{
${ }^{6}$ Por. zarmenizowany leksem genetycznie grecki.

${ }^{7}$ Por. zarmenizowany leksem genetycznie egipski.

${ }^{8} \mathrm{~W}$ tym: pahlawi.

${ }^{9}$ Por. zarmenizowany leksem genetycznie persko-turecki.

${ }^{10}$ Por. leksem genetycznie ormiański.

${ }^{11}$ Por. zarmenizowany leksem genetycznie perski.
} 
Dongiewicz, Doniegiewicz, Tonikiewicz - orm. Tonik z fon. zachorm. (Do$n i g$ ) > pol. Tonik, Donig (Donieg z obniżeniem artykulacji $i$ do e, Dong z zanikiem - $i-\mathrm{w}$ sylabie wygłosowej), w temacie alternacja $g: g^{\prime}, k: k^{\prime}$; Kirkorowicz, Kierkorowicz - orm. Grigor z fon. zachorm. (Krikor/Kirkor) > pol. Kirkor (Kierkor z obniżeniem artykulacji $i$ do e); Manugiewicz, Manukiewicz - orm. Manuk z fon. zachorm. (Manug) > pol. Manug, Manuk, w temacie alternacja $g: g^{\prime}, k: k^{\prime}$; Minasiewicz, Minasowicz, Minaszewicz, Miniasiewicz - orm. Minas > pol. Minas, Minasz (Minias ze zmiękczeniem $n: \grave{n}$ ), w temacie alternacja $s: \grave{s}: \check{s}$ (mieszanie spółgłosek szczelinowych); Norsesowicz - orm. Nerses $>$ pol. Norses z zastąpieniem samogłoski średniej (przedniej) e średnią (tylną) o; Ohanowicz/Ochanowicz - pol. O(c)han < orm. Ohan; Piramowicz, Pirmowicz, Pirianowicz/Pirijanowicz/Pirjanowiczorm. $P$ 'iran $>$ pol. Piram (Pirm z zanikiem $-a-\mathrm{w}$ sylabie wygłosowej) z wahaniem spółgłosek nosowych $m / n$ (Pirian/Pirjan/Pirijan ze zmiękczeniem $r: r^{\prime}$ ) lub orm. P'irum $>$ pol. Piram z zastąpieniem samogłoski $u$ samogłoską $a$ (obniżenie artykulacji $u$ do $o$, następnie $o$ do $a$ ); Torosiewicz - orm. T'oros $>$ pol. Toros, w temacie alternacja $s: s$; Wachanowicz - pol. Wa(c)han < orm. Vahan; Wartanowicz, Wartonowicz - orm. Vardan z fon. zachorm. (Vartan) $>$ pol. Wartan (Warton z podwyższeniem artykulacji $a$ do o); Warteresiewicz orm. Varderes $\mathrm{z}$ fon. zachorm. (Varteres) $>$ pol. Warteres, w temacie alternacja $s: s$; Wartykiewicz - orm. Vardik z fon. zachorm. (Vartig) $>$ pol. Wartyk z pol. $y$ na miejscu orm. $i$ oraz stwardnieniem spółgłoski poprzedzającej, w wygłosie ubezdźwięcznienie, w temacie alternacja $k: k^{\prime}$; Zadurowicz, Żadurowicz - orm. Zadur > pol. Zadur (Żadur - z szadzeniem, mieszanie spółgłosek szczelinowych z/ž); Zadygowicz, Zadykowicz, Zadykiewicz - orm. Zatik z fon. zachorm. (Zadig) > pol. Zadyg z pol. y na miejscu orm. $i$ oraz stwardnieniem spółgłoski poprzedzającej (Zadyk - ubezdźwięcznienie $\mathrm{w}$ wygłosie, w temacie również $\mathrm{z}$ alternacją $k: k^{\prime}$ ); Zarugiewicz, Zarukiewicz, Zerygiewicz, Żerygiewicz - orm. Zaruk z fon. zachorm. (Zarug) > pol. Zarug, Zaruk (Zeryg z podwyższeniem artykulacji $a$ do e, Żeryg z szadzeniem, mieszanie spółgłosek szczelinowych $z / z ̌$ ) lub orm. Zeruk z fon. zachorm. (Zerug) > pol. Zeryg z zastąpieniem samogłoski wysokiej/wąskiej (tylnej) $u$ wysoką/wąską (przednią) y (Zarug/Zaruk z obniżeniem artykulacji $e$ do $a$, wahanie w wygłosie dźwięczna/bezdźwięczna), w temacie alternacja $g: g^{\prime}, k: k^{\prime}$. 


\section{SKRÓTY I ZNAKI}

$\begin{array}{ll}\text { ap. } & \text { - apelatyw } \\ \text { asyr. } & \text { - asyryjski } \\ \text { bibl. } & \text { - biblijny } \\ \text { czes. } & \text { - czeski } \\ \text { egip. } & \text { - egipski } \\ \text { fon. } & \text { - fonetyka } \\ \text { gr. } & - \text { grecki } \\ \text { gw. } & - \text { gwarowy } \\ \text { im. } & - \text { imię } \\ \text { im. zł. } & \text { - imię złożone } \\ \text { łac. } & \text { - łaciński } \\ \text { n. } & \text { - nazwa } \\ \text { n. m. } & \text { - nazwa miejscowa } \\ \text { n. os. } & \text { - nazwa osobowa } \\ \text { niem. } & \text { - niemiecki } \\ \text { orm. } & \text { - ormiański }\end{array}$

pahl. - pahlawi (średnioperski)

pers. - perski

podst. - podstawa

pol. - polski, polonizacja

por. - porównaj

stp. $\quad-$ staropolski

suf. $\quad-$ sufiks

tur. $\quad-$ turecki

ukr. - ukraiński

wsł. - wschodniosłowiański

zachorm. - zachodnioormiański

zob. $\quad-$ zobacz

: $\quad-$ pochodzący od

$<\quad-$ znak relacji pochodności

, $\quad$ znaczenie wyrazu

\section{SKRÓTY NAZW WOJEWÓDZTW OD 1975 DO 31 GRUDNIA 1998}

BB - bielskie, BP - bialskopodlaskie, Bs - białostockie, By - bydgoskie, C - chełmskie, Ci ciechanowskie, $\mathrm{Cz}$ - częstochowskie, El - elbląskie, Gd - gdańskie, Go - gorzowskie, JG jeleniogórskie, $\mathrm{Ka}$ - katowickie, Ki - kieleckie, Kl - kaliskie, Kn - konińskie, Ko - koszalińskie, $\mathrm{Kr}$ - krakowskie, Ks - krośnieńskie, Lg - legnickie, Ls - leszczyńskie, Lu - lubelskie, Łd łódzkie, Ło - łomżyńskie, NS - nowosądeckie, Ol - olsztyńskie, Op - opolskie, Os - ostrołęckie, $\mathrm{Pl}$ - pilskie, $\mathrm{P}$ - płockie, $\mathrm{Po}$ - poznańskie, $\mathrm{Pr}$ - przemyskie, $\mathrm{Pt}$ - piotrkowskie, $\mathrm{Ra}$ - radomskie, $\mathrm{Rz}$ - rzeszowskie, $\mathrm{Sd}$ - siedleckie, $\mathrm{Sk}$ - skierniewickie, $\mathrm{S} ł$ - słupskie, $\mathrm{Sr}$ - sieradzkie, $\mathrm{Su}$ suwalskie, $\mathrm{Sz}$ - szczecińskie, Ta - tarnowskie, Tb - tarnobrzeskie, To - toruńskie, Wa warszawskie, $\mathrm{Wb}$ - wałbrzyskie, $\mathrm{Wl}$ - włocławskie, $\mathrm{Wr}$ - wrocławskie, $\mathrm{Za}$ - zamojskie, ZG zielonogórskie

\section{BIBLIOGRAFIA}

Avetisyan, Tigran. Hayoc 'azganunneri bararan. Hełinakayin hratarakut'yun, 2010.

Barącz, Sadok. Rys dziejów ormiańskich. Tarnopol 1869.

Barącz, Sadok. Żywoty stawnych Ormian w Polsce. Lwów 1856.

Buczyński, Mieczysław. „Patronimika ormiańskie w XVII-wiecznym Zamościu”. Wpływy obce w nazewnictwie Polski, red. Maria Kamińska, Wydawnictwo Uniwersytetu Łódzkiego, 1993, ss. $23-30$. 
Bystroń, Jan. Nazwiska polskie. Książnica - Atlas, 1936.

Cieślikowa, Aleksandra, i in., red. Antroponimia Polski od XVI do końca XVIII wieku, t. 1-6, Wydawnictwo Lexis (t. 1-3), Instytut Języka Polskiego PAN (t. 4-6), 2007-2016.

Hanusz, Jan. „Einige slavische Namen armenischer und türkischer Herkunft”. Archiv für slavische Philologie, Band 9, 1886, pp. 472-477.

Hanusz, Jan. „O nazwiskach Ormian polskich”. Muzeum, z. 10, 1886, ss. 565-573.

Kaleta, Zofia. Ewolucja nazwisk słowiańskich. Studium teoretyczno-porównawcze. Polska Akademia Nauk. Instytut Języka Polskiego, 1991.

Kaleta, Zofia. „Teoria nazw własnych”. Polskie nazwy własne. Encyklopedia, red. Ewa Rzetelska-Feleszko, Wydawnictwo Instytutu Języka Polskiego PAN, 2005, ss. 15-36.

Machul-Telus, Beata, red. Ormianie. Wydawnictwo Sejmowe, 2014.

Magda-Czekaj, Małgorzata. Wybrane typy słowotwórcze nazwisk (-icz, -owicz, -ewicz i z podstawowym -k-) okresu średniopolskiego w ujęciu historyczno-spolecznym. Wydawnictwo Instytutu Języka Polskiego PAN, 2011.

Malec, Maria, oprac. Stownik etymologiczno-motywacyjny staropolskich nazw osobowych, cz. 2: Nazwy osobowe pochodzenia chrześcijańskiego. Polska Akademia Nauk. Instytut Języka Polskiego, 1995.

Pisowicz, Andrzej, oprac. „Nazwy osobowe Ormian. Próba objaśnienia”. Stownik etymologiczno-motywacyjny staropolskich nazw osobowych, cz. 7: Suplement. Rozwiazanie licznych zagadek staropolskiej antroponimii, red. Aleksandra Cieślikowa, Wydawnictwo Naukowe DWN, 2002, ss. 31-41.

Rymut, Kazimierz. „Nazwiska”. Polskie nazwy własne. Encyklopedia, red. Ewa Rzetelska-Feleszko, Wydawnictwo Instytutu Języka Polskiego PAN, 2005, ss. 143-160.

Rymut, Kazimierz. Nazwiska Polaków. Słownik historyczno-etymologiczny, t. 1-2, Wydawnictwo Instytutu Języka Polskiego PAN (t. 1), Wydawnictwo Naukowe DWN (t. 2), 1999-2001.

Rymut, Kazimierz. Słownik nazwisk wspótcześnie w Polsce używanych, t. 1-10, Polska Akademia Nauk. Instytut Języka Polskiego, 1992-1994.

Słuszkiewicz, Eugeniusz. „Orm. Minasowicz || Minasiewicz itp.” Język Polski, nr 1, 1956, ss. 42-44.

Stopka, Krzysztof. Ormianie w Polsce dawnej i dzisiejszej. Księgarnia Akademicka, 2000.

Stopka, Krzysztof, i Andrzej Zięba. Ormiańska Polska = Hayoc'Lehastanə = Armenian Poland . Fundacja Kultury i Dziedzictwa Ormian Polskich, Ormiańskie Towarzystwo Kulturalne, 2018.

Taszycki, Witold, i in., red. Stownik staropolskich nazw osobowych, t. 1-7. Zakład Narodowy Imienia Ossolińskich. Wydawnictwo Polskiej Akademii Nauk, 1965-1987.

Vardanân, Liliâ, et al. ed. Armâne. Nauka, 2012.

Wasyl, Franciszek. Ormianie w przedautonomicznej Galicji. Studium demograficzno-historyczne. Księgarnia Akademicka, 2015.

Wolnicz-Pawłowska, Ewa, i Wanda Szulowska. Antroponimia polska na Kresach poludniowo-wschodnich XV-XIX wiek. Slawistyczny Ośrodek Wydawniczy, 1998.

Zakrzewska-Dubasowa, Mirosława. Ormianie w dawnej Polsce. Wydawnictwo Lubelskie, 1982. 


\title{
WSPÓŁCZESNE POLSKIE NAZWISKA PATRONIMICZNE \\ (Z SUFIKSAMI -ICZ, -OWICZ/-EWICZ) \\ POCHODZENIA ORMIAŃSKIEGO
}

\author{
Streszczenie
}

Przedmiotem artykułu są współczesne polskie nazwiska patronimiczne (z formantami -icz, -owicz / -ewicz), które zawdzięczają pochodzenie (lub też mogą zawdzięczać) leksemom ormiańskim (zaliczam do nich również zarmenizowane antroponimy genetycznie obce). Pierwsi Ormianie - posługujący się językiem kipczackim - przybyli na ziemie polskie w XIV wieku. W XVIII wieku na Kresach Południowo-Wschodnich pojawiła się kolejna ormiańska fala migracyjna, przybysze posługiwali się dialektem należącym do grupy zachodnioormiańskiej. Otoczenie słowiańskie (polskie i ruskie - ukraińskie) wpływało na stopniową slawizację ormiańskich antroponimów: kipczackie leksemy czy ormiańskie sufiksy patronimiczne zastępowano słowiańskimi sufiksami patronimicznymi. W opracowaniu zawarto 57 antroponimów (ujętych w 25 hasłach słownikowych), które pochodzą (lub mogą pochodzić) od ormiańskich onimów.

Słowa kluczowe: antroponimia; nazwiska; nazwiska polskie; Ormianie w Polsce; język ormiański; nazwiska ormiańskie.

\author{
MODERN POLISH PATRONYMIC SURNAMES \\ (WITH SUFFIXES SUCH AS -ICZ, -OWICZ/-EWICZ) \\ OF ARMENIAN ORIGIN
}

S u m m a ry

The main topic of this article are modern Polish patronymic surnames (with the suffixes -icz, -owicz/-ewicz), whose origins can be pointed to, or are owed to, Armenian lexemes (the author also encompasses Armenianised anthroponyms which are hereditarily foreign). The first Armenians-who used the Kipchak language-arrived in Polish lands in the 14th century. During the 18th century, in the South-Eastern Borderlands, a new Armenian wave of migrants arrived; the newcomers used to communicate in a dialect which belonged to the Western Armenian group of dialects. The Slavic surroundings they found themselves in (Polish and Ruthenian-Ukrainian) gradually influenced the Armenian anthroponyms: both Kipchak lexemes and Armenian patronymic suffixes were modified with Slavic patronymic suffixes. In this article, there are presented 57 anthroponyms (contained in 25 dictionary entries) which originate from, or may come from, Armenian proper nouns.

Key words: anthroponymy; surnames; Polish surnames; Armenians in Poland; Armenian language; Armenian surnames. 